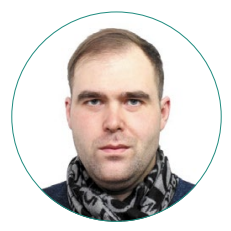

\author{
К.А. Галкин
}

\title{
"КАК В ТАЙГЕ ИЛИ ГЛУБОКОМ КОСМОСЕ": ТЕМАТИЧЕСКИЙ АНАЛИЗ СМЫСЛОВ РАБОТЫ И ПОВСЕДНЕВНОСТИ МОЛОДЫХ СЕЛЬСКИХ ВРАЧЕЙ В ПЕРИОД ПАНДЕМИИ COVID-19
}

\section{Правильная ссылка на статью:}

Галкин К.А. «Как в тайге или глубоком космосе»: тематический анализ смыслов работы и повседневности молодых сельских врачей в период пандемии COVID-19// Мониторинг общественного мнения: экономические и социальные перемены. 2021. № 3. С. 41-56. https://doi.org/10.14515/monitoring.2021.3.1864.

\section{For citation:}

Galkin K. A. (2021) “Like in the Taiga or Deep Space”: A Thematic Analysis of the Meanings of the Work and Everyday Life of Young Country Doctors During the COVID-19 Pandemic. Monitoring of Public Opinion: Economic and Social Changes. No. 3. P. 41-56. https://doi.org/10.14515/ monitoring.2021.3.1864. (In Russ.) 
«КАК В ТАЙГЕ ИЛИ ГЛУБОКОМ КОСМОСЕ»: ТЕМАТИЧЕСКИЙ АНАЛИЗ СМЫСЛОВ РАБОТЫ И ПОВСЕДНЕВНОСТИ МОЛОДЫХ СЕЛЬСКИХ ВРАЧЕЙ В ПЕРИОД ПАНДЕМИИ COVID-19

ГАЛКИН Константин Александрович - кандидат социологических наук, старший научный сотрудник, Социологический институт Федерального научно-исследовательского социологического центра Российской академии наук, Санкт-Петербург, Россия

E-MAIL: Kgalkin1989@mail.ru https://orcid.org/0000-0002-6403-6083

Аннотация. Пандемия COVID-19 изменила график работы многих профессионалов. Для специалистов в области медицины, в частности для врачей, ситуация с пандемией была связана отнюдь не с переходом на удаленный график работы, а с дополнительными нагрузками и необходимостью перестраивать привычный распорядок дня и расширять профессиональные компетенции, в том числе привыкать к работе с бо́льшим количеством пациентов. В сельской местности, как правило, наблюдается дефицит врачей, и докторам из одного фельдшерскоакушерского пункта или амбулатории приходится обслуживать несколько деревень, которые могут быть удалены друг от друга на расстояние до десяти километров. Цель настоящей статьи описать субъективные интерпретации смыслов работы сельских врачей в период пандемии COVID-19.

Работа выполнена в русле феноменологического подхода к исследованию профессий, позволившего рассмотреть нарратив молодых врачей и проанализировать особенности их повседневно-
“LIKE IN THE TAIGA OR DEEP SPACE": A THEMATIC ANALYSIS OF THE MEANINGS OF THE WORK AND EVERYDAY LIFE OF YOUNG COUNTRY DOCTORS DURING THE COVID-19 PANDEMIC

Konstantin A. GALKIN ${ }^{1}$ - Cand. Sci. (Soc.), Senior Researcher E-MAIL: Kgalkin1989@mail.ru https://orcid.org/0000-0002-6403-6083

\footnotetext{
${ }^{1}$ Sociological Institute, Federal Center of Theoretical and Applied Sociology, Russian Academy of Sciences, St. Petersburg, Russia
}

Abstract. The COVID-19 pandemic has changed the work of many professionals. For medical ones, in particular for doctors, the situation caused by the pandemic has been associated not only with the transition to a remote work, but also with additional workloads, the need to restructure the daily routine and expand professional competencies, for example, to get used to working with a larger number of patients. As a rule, there is a shortage of doctors in rural areas, so one doctor has to serve several villages, which can be located at a distance of up to ten kilometers from each other. The purpose of this article is to describe the subjective meanings that country doctors give to their work during the COVID-19 pandemic.

The work was done in the framework of a phenomenological approach to the study of professions, which allows to analyze narratives of young country doctors and emphasize features of their everyday life. Utilizing the method of thematic analysis, the article focuses on the following main topics: 1) transformation of the doctor's role, 2 ) changes in motivation, and 3 ) 
сти. Основной метод - тематический анализ нарративов интервью, где в качестве главных тем были выделены 1) трансформация роли врача, 2) изменения мотивации и 3) вопросы удовлетворенности работой в сельской местности в период пандемии. С помощью метода полуструктурированных интервью с молодыми сельскими врачами на материале кейсов двух регионов Ленинградской области и Республики Карелия - в статье предпринимается попытка нарративного описания смыслов повседневной работы молодых врачей в период COVID-19.

Ключевые слова: пандемия COVID-19, молодые врачи в сельской местности, особенности работы молодых сельских врачей, мотивация молодых врачей в сельской местности, удовлетворенность молодых врачей работой, тематический анализ issues of job satisfaction in rural areas during the pandemic. Semi-structured interviews with young country doctors were conducted in two regions - the Leningrad Region and the Republic of Karelia. On their basis, the article represents the meanings that young doctors put into their work during the period of COVID-19.

\begin{abstract}
Keywords: COVID-19 pandemic, young doctors in rural areas, motivation of young doctors in rural areas during the COVID-19 pandemic, thematic analysis, features of the work of young country doctors, job satisfaction among young doctors
\end{abstract}

\section{Введение}

Ученые, изучающие сельско-городские различия, акцентируют внимание на анализе особенностей конкретных социально-экономических сфер. В фокусе многих исследований находятся профессиональные характеристики и условия работы, специфика построения карьер на селе и в городе [Woods, 2012; Широкалова, Дерябина, 2010; Гранберг, 2015].

В спектр внимания социальных исследователей попадает профессия врача на селе, которая ввиду особенностей социальной ткани сельских сообществ отличается от профессии городского врача функционалом и иными профессиональными задачами [Вяткина, Вахромеева, 2012; Галкин, 2019; Галкин, 2020].

Различные исследования показывают ухудшение условий труда сельских врачей и одновременный рост требований к их работе, что приводит к быстрому снижению уровня мотивации медицинских профессионалов [Семина, 2015; Шилова, 2013]. Важными аспектами в данном контексте выступают повышение стрессогенности работы и необходимость выполнения слишком разных профессиональных задач [Петрова, 2014; Андреева, 2020; Kumar, 2016; Amoafo, Hanbali, Patel, Singh, 2015]. К нарушению баланса труда и отдыха, а также снижению трудовой мотивации сельских врачей приводят и различные чрезвычайные ситуации, создающие жесткие и сложные условия для работы. 
На материалах серии полуструктурированных интервью с молодыми сельскими врачами, собранных в двух регионах - Ленинградской области и Республики Карелия, в данной статье мы предпринимаем попытку рассмотреть особенности повседневности и работы молодых сельских врачей в период пандемии COVID-19, изучить, как меняется их мотивация.

Исследование молодых врачей позволяет проанализировать, как трансформируются и изменяются смыслы профессии и работа молодых профессионалов в сельской местности, каковы модели их взаимодействия с пациентами и мотивация продолжать работу на селе. В группу молодых врачей были включены специалисты, имеющие высшее медицинское образование и стаж работы в сельской местности от одного года до пяти лет. Возраст информантов - от 25 до 34 лет.

\section{Эмпирическая база и методология исследования}

Эмпирической базой настоящего исследования выступают данные тридцати полуструктурированных интервью, проведенных в Лужском районе Ленинградской области и Питкярантском районе Республики Карелия с апреля по август 2020 г. В каждом регионе было опрошено по пятнадцать молодых врачей. При планировании выборки мы учитывали различия в количестве и оснащенности ФАПов ${ }^{1}$ и амбулаторий, а также особенности реализации программы “Земский доктор", существующие в выбранных территориях. Эти характеристики были важны для формирования выборки, так как учитывались наиболее контрастные кейсы, отличающиеся по численности пациентов и оснащенности в двух исследовательских локациях. Так, в Лужском районе Ленинградской области большинство ФАПов оснащены компьютерами с доступом в интернет, в то время как в Питкярантском районе на момент проведения исследования только два ФАПа были оборудованы компьютерами с доступом в сеть ${ }^{2}$. В интервью специалисты говорили нам, что это одно из важных условий, влияющих на их трудовую мотивацию.

Сбор данных осуществлялся в методологии феноменологического подхода [Романов, Ярская-Смирнова, 2009]. Задача интервьюера заключалась в изучении особенностей повседневных практик молодых врачей, специфических характеристик их удовлетворенности работой, в выявлении субъективных смыслов, вкладываемых ими в медицинскую профессию.

При обработке текстов интервью мы использовали метод секвенциального анализа, который подразумевает, что особенности социальных структур изучаются в их взаимодействиях [Miles, Huberman, 1994; Alhojailan, 2012; Kvale, 1996] и что социальные структуры оказывают влияние на повседневную жизнь, создавая системы смыслов, отражаемые в нарративах [Майвальд, 2011]. В исследовании

\footnotetext{
1 ФАП- фельдшерско-акушерский пункт.

2 ОНФ: ФАПы Карелии нуждаются в ремонтах и оснащении кадрами и оборудованием // Столица Onego. 2018. 20 сентября. URL: https://stolicaonego.ru/news/onf-fapy-karelii-nuzhdajutsja-v-remontah-i-osnaschenii-kadrami-ioborudovaniem/ (дата обращения: 16.04.2021); Ленобласть завершает масштабную программу строительства ФАПов // 47 Channel. 2019. 14 августа. URL: https://47channel.ru/event/Lenoblast_zavershaet_masshtabnuyu_ programmu_stroitelstva_FAPov (дата обращения: 16.04.2021); В Ленобласти форсируют строительство ФАПов //Online 47.ru. 2020. 16 января. URL: https://online47.ru/2020/01/16/v-lenoblasti-forsiruyut-stroitelstvo-fapov-85210 (дата обращения: 16.04.2021); За 614 млн рублей в Ленобласти построят ФАП и два амбулаторных центра // 47 News. 2020. 22 апреля. URL: https://47news.ru/articles/173090/ (дата обращения: 16.04.2021).
} 
применялся особый тип секвенциального анализа - конверсационный анализ, предполагающий соблюдение ряда принципов.

Во-первых, это анализ конкретных случаев и взаимодействий акторов, предшествующий сравнению и генерализации. Руководствуясь данным принципом, в транскриптах интервью мы выделяли смысловые структуры, которые затем легли в основу описания ситуаций, присутствующих в повседневной жизни молодых врачей. Так, сначала мы идентифицировали секвенции - части транскрипта интервью, отражающие ключевые для исследования темы: трансформация роли врача, изменения мотивации и вопросы удовлетворенности работой в сельской местности в период пандемии COVID-19.

Во-вторых, это анализ циклов, присутствующих в обозначенных секвенциях. На первом этапе данного анализа рассматривалась избирательность каждого из направлений (тем, которые перечислены выше), устанавливались связи между удовлетворенностью, мотивацией, и пандемией при работе молодых врачей в сельской местности. На втором этапе анализа циклов исследовались контексты и ожидания говорящего. Здесь мы уделяли внимание эмоциональным оттенкам и контекстам нарративов - особенностям историй о проблемах и сложностях работы в период распространения COVID-19. Третий этап анализа циклов был связан с обозначением ключевых субтем, используя которые, молодые врачи описывали ситуацию пандемии через следующие формулировки: “отсутствие времени заниматься профилактическими работами"; "новые обязанности", "необходимость лечения нового заболевания, которое требует новых знаний и новых навыков, что требует дополнительного времени»; "наличие средств индивидуальной защиты (СИЗ)"; "отсутствие возможностей для баланса между работой и отдыхом»; "потеря экспертности и профессионализма»; «администрирование в системе здравоохранения»; "защита местного сообщества»; "охранная роль в местном сообществе»; "особая роль медицинского специалиста на селе".

Затем нами были обозначены взаимосвязи циклов и высказываний информантов. При анализе интервью большое внимание уделялось исследованию смыслов, вкладываемых в коммуникативные модели, в рамках которых участники исследования говорили об особенностях работы молодых сельских врачей в период пандемии COVID-19. Далее мы проанализировали темы и субтемы, посредством которых информанты описывали свою работу в период пандемии. Субтемы были выделены методом группировки данных в соответствии с семантико-смысловым содержанием высказываний и исходя из трех ключевых тем исследования.

Ограничения результатов исследования заключаются в небольшой выборке (сравнении двух регионов).

\section{Трудовая повседневность, мотивация и удовлетворенность молодых сельских врачей}

Мотивация сельских врачей к работе и связь между мотивацией и удовлетворенностью работой - вот темы, которые сегодня активно изучаются в рамках различных научных дисциплин - социологии медицины, медицинской антропологии, управления сельскими территориями, экономики сельских территорий. 
Д. Патман и соавторы отмечают, что один из результативных способов повышения у молодых врачей мотивации к работе в сельской местности - это создание специальных мотивационных программ [Pathman et al., 2004: 1723]. Такие программы действуют в разных странах мира и стимулируют желание специалистов ехать работать в села.

В России тоже существует подобная программа - «Земский доктор». Изначально она предназначалась для специалистов в возрасте до 35 лет, но в 2019 г. возраст участников был увеличен до 50 лет ${ }^{3}$. Как отмечают исследователи, мотивацию молодых врачей к работе в сельской местности снижают в первую очередь отсутствие карьерных перспектив, сложности с многозадачностью, устаревшее и отсутствующее оборудование, нехватка коллегиальности, необходимой для принятия решений молодыми врачами [Галкин, 2018; Дьяченко, Костакова, Пригорнев, 2011; Serneels et al., 2010]. Безусловно, часть этих факторов может влиять и на трудовую мотивацию городских врачей, однако проблемы, связанные с многозадачностью и отсутствием перспектив, в наибольшей степени затрагивают медицинских профессионалов, работающих на селе. Следует отметить, что на снижение мотивации сельских врачей влияют и возросшие требования по заполнению документации. Если у городского врача при этом есть возможность использовать компьютер, то в сельской местности из-за инфраструктурного дефицита и отсутствия интернета докторам нередко приходится заполнять необходимые документы от руки.

В ряде исследований установлено, что сельские врачи в большей степени удовлетворены трудом в тех случаях, когда обладают профессиональной автономией, а результативность их работы оценивается профессиональным, а не местным сообществом. Это обусловлено тем, что ввиду плотности социальной ткани жители села считают возможным вмешиваться в работу специалистов, диктуя им определенные условия, например, оценивать необходимость медицинской помощи тому или иному пациенту, исходя из его заслуг перед сельским сообществом [Budhathoki et al., 2017; Галкин, 2019; Чирикова, 2019]. По результатам других исследований, наоборот, сельские врачи имеют бо́льшую профессиональную автономию, чем городские врачи, что позитивно сказывается на мотивации и желании работать в сельской местности [Kusurkar et al., 2011; Ohta, Ryu, Otani, 2020; Driever, Stiggelbout, Brand, 2020]. Ключевым критерием профессиональной автономии в подобных исследованиях выступает врачебный патернализм, который возможен именно на селе, где медицинская профессия приобретает особую экспертность.

Монополия сельского врача на экспертные знания ограничивается особенностями его труда и взаимодействия с пациентами в конкретном поселении, а также различными ситуациями, возникающими в рамках его профессиональной деятельности. Однако врачебный патернализм и экспертные знания не только в области лечения пациентов, но и решения множества возникающих проблем по-прежнему остаются значимыми характеристиками работы медиков на селе.

Исследователи, изучающие профессиональные проблемы молодых врачей, отмечают сложности, возникающие у них при интеграции в сельское сообщество, и конфликты, связанные с разграничением ролей профессионала и местного

\footnotetext{
з Федеральный закон "Об обязательном медицинском страховании в Российской Федерации" от 29.11.2010 № 326-Ф3.
} 
жителя [Галкин, 2018; Галкин, 2019]. Одним из важных факторов успешности для сельских врачей оказывается их вовлеченность в местное сообщество, которая выступает одновременно возможностью для построения успешной "сельской" карьеры и защитой от возможного профессионального выгорания. Этот фактор влияет как на удовлетворенность молодых врачей работой, так и на мотивацию к ее продолжению [Saijo, Yoshioka et al., 2018; Кобякова и др., 2017].

В ситуации распространения COVID-19 обостряются все сложности и трудности, характерные для сельской медицины, в частности проблемы, связанные с отсутствием коллегиальных советов и своевременным информированием о методах лечения новой коронавирусной инфекции, нехватка средств индивидуальной защиты, большое количество пациентов и многозадачность [Glenister, Ervin, Podubinski, 2021]. Все это формирует особую обстановку работы специалистов в сельской местности и вкладывает новые смыслы в понимание профессии сельского врача в период кризисной ситуации. Кроме того, в контексте пандемии усиливается стрессогенность в работе врачей, связанная как с риском оказать помощь неправильно, так и с риском заражения новой инфекцией.

В основе нашего исследования лежит феноменологический подход к изучению профессий, в рамках которого профессия определяется как достаточно замкнутый жизненный мир работников с его специфическими проблемами и трудностями [Todd et al., 2016]. С позиции феноменологического подхода, важной составляющей профессиональной деятельности выступает идентификация индивида с той или иной профессиональной сферой. Смыслы, характеризующие профессиональную деятельность, определяют и принадлежность к профессии [Романов, ЯрскаяСмирнова, 2011]. Исходя из этого концептуального положения, в нашем исследовании мы фокусируем внимание на анализе смыслов и тем, в рамках которых молодые врачи описывают свою профессиональную деятельность и особенности работы в период пандемии COVID-19.

\section{Изменения мотивации и удовлетворенности работой у молодых сельских врачей}

Те части нарративов молодых врачей, где они говорят об особенностях и последствиях пандемии, отличает рефлексия о проблемах в работе, которые сопровождали информирование о положении дел. Молодые врачи весьма эмоционально описывают особенности изменений бюджетов времени, особенно если это касается работы с пациентами и возрастающей нагрузки.

B условиях пандемии COVID-19 увеличивающаяся нагрузка и многозадачность, связанные прежде всего с профилактической деятельностью, становятся важной частью работы молодых сельских врачей. При этом профилактическая деятельность рассматривается ими как отвлекающая от основной работы и даже препятствующая повышению ее продуктивности. В этом контексте некоторые информанты следующим образом говорят о несправедливости в распределении рабочего времени:

Вот уже с начала апреля из ЦРБ пришло распределение о необходимости заниматься так называемой просветительской деятельностью: рассказывать, по сути, о неизвест- 
ной болезни здесь, в селе. И это сложно: во-первых, ты сам о болезни ничего не знаешь в принципе, а во-вторых, знаете, мы же врачи и должны лечить, а не как сейчас я: на приеме пациентов сказки рассказываю и в библиотеке для всего села нотации читаю о пользе масок. (М., 29, терапевт, Республика Карелия) ${ }^{4}$

Информанты отмечают, что это задает «дополнительную психологическую нагрузку". В нарративах молодых врачей встречаются эмоциональные отсылки, связанные с описанием сложностей, труднодоступности и невыполнимости профессиональных обязанностей в период пандемии COVID-19. В результате анализа интервью нами было выделено три субтемы, описывающие недовольство информантов изменениями, связанными с распределением нагрузки:

1) «отсутствие времени заниматься профилактическими работами»;

2) «новые обязанности»;

3) «необходимость лечения нового заболевания, которое требует новых знаний и навыков, что требует дополнительного времени".

Информанты описывали свой опыт работы, используя метафору хаоса, когда ситуация создает дистресс и профессиональные обязанности становятся невнятными. В нарративах молодых сельских врачей метафора хаоса встречалась в основном при описании их работы сейчас (в период пандемии), а также при описании новых профессиональных обязанностей и функционала. В эти моменты речь информантов становилась быстрой, они делали длинные паузы и голосом выделяли ключевые проблемы, с которыми столкнулись:

Теперь вообще просто мрак непролазный выходит. Потому что все время теперь то к ковидным ехать надо, то вообще бывает так, что, пока скорая не приедет, по два-три часа надо ждать. И еще боишься, когда сидишь у больного, ведь заразиться довольно легко. (Ж., 27, терапевт, Ленинградская область)

Говоря о многозадачности и несправедливости распределения нагрузки, информанты поднимали субтему сельскости, то есть сложностей, связанных с сельской местностью, прежде всего с тем, что в отличие от городов на селе нет необходимого контингента врачей, отсутствует возможность обратиться за помощью к коллеге и распределить свое время. При анализе текстов интервью мы отметили различия между молодыми врачами из Ленинградской области и Питкярантского района Республики Карелия, связанные с сюжетом многозадачности и несправедливости в распределении нагрузки. Данный сюжет в большей степени оказался характерен для докторов Питкярантского района, и в меньшей - для врачей из Ленинградской области, где имеется большой контингент соответствующих специалистов.

Субтема сельскости артикулировалась в нарративе с помощью использования метафоры хаоса, а также была вписана в субтему необходимости лечения заболевания, которое требует новых знаний, навыков и дополнительного времени:

Считай, это раньше было легко, а теперь нет. Теперь же - сам, наверное, понимаешь, чтобы тот же ковид излечить, нужно очень сильно постараться да извернуться. Потому

\footnotetext{
4 Здесь и далее в сведениях об информанте: «М» означает «мужчина», “Ж”- "Женщина», а последующие цифры—возраст.
} 
что теперь же необходимо больше читать, а это значит, что просто тупо больше сидеть в том же "нете». И вот поэтому приходится выбирать между своими обязанностями: или просто лечить какое-нибудь заболевание хроническое у пожилых, или в итоге лечить ковид. (М., 32, врач общей практики, Республика Карелия)

Метафоричное описание хаоса и то, что стоит за ним, было для них источником волнений и связывалась с недовольством по поводу администрирования системы здравоохранения в период COVID-19. Так, мы выделили в нарративах три субтемы, описывающие недовольство докторов при работе в сельской местности и их волнение из-за возможности заразиться либо вовремя не оказать помощь пациентам:

1) "Отсутствие средств индивидуальной защиты (СИЗ)",

2) "Отсутствие возможностей для баланса между работой и отдыхом",

3) «Потеря экспертности и профессионализма».

Эти субтемы служили основой для субъективной трансформации смысла медицинской профессии, связанной с ситуацией пандемии COVID-19. Эти изменения прежде всего касались потери экспертности и проявлялись в нарративах через описание непредсказуемости и непонимания, отсутствия уверенности в завтрашнем дне:

Сейчас очень тяжелое время, и эта пандемия, по-моему, полностью показала, что наша медицина - и не только российская, но и мировая, - не готова вообще к таким вызовам в принципе. И поэтому, когда пациенты, знаете ли, вот так становятся экспертами и пытаются диктовать тебе правильность лечения и помощи, то это вообще становится абсолютно невыносимым и дико раздражает. Уже перестаешь себя врачом ощущать. (Ж., 27, врач общей практики, Республика Карелия)

Как в тайге или глубоком космосе, в общем-то. Ситуации, одним словом, схожие. Потому что мы здесь, в отличие от наших городских коллег, должны к пациенту голыми идти. Ни СИЗов, ни тестов. И, конечно, это риск как для своего собственного здоровья, так и для здоровья пациентов. (М., 34, терапевт, Республика Карелия)

Для обозначения пассивной позиции врачей мы используем термин «профессиональный фатализм", характеризующий нарративы, в которых работа докторов в сельской местности в период пандемии COVID-19 описывается с позиций жертвы. Мы используем термин "фатализм", чтобы подчеркнуть отсутствие у информантов возможностей для развития в профессии, а также их ощущение возрастающей нагрузки при недостаточности навыков, позволяющих правильно диагностировать и лечить новую болезнь. В этом контексте в нарративах информантов появляется еще одна важная субтема, описывающая трансформацию медицинской профессии,- субтема уязвимости. Она связана прежде всего с отсутствием ощущения своего профессионализма, возможности справиться с заболеванием, как это было раньше в практике врачей:

Как будто и не училась я вовсе. Вот такие, наверное, ощущения, и больше ничего в принципе. А возникают эти ощущения, думаю, потому, что я просто не знаю, что 
дальше, да и никто не знает. Но если в городах, положим, все же есть какие-то эксперты, которые могут собраться и к которым ты в принципе можешь обратиться, то здесь, в селе, вообще ничего такого нет. По сути, здесь врач сам себе предоставлен. И вот это, конечно, настораживает и заставляет задуматься над тем, как дальше жить и работать. (Ж., 29, терапевт, Ленинградская область)

Администрирование в системе здравоохранения описывалось в нарративах молодых врачей как неэффективное. Не налаженное администрирование снижало мотивацию молодых врачей.

Я не знаю, что дальше будет, да и знать это тоже достаточно сложно. Но что точно сейчас можно сказать наверняка, так это сказать о том, что проблема возникает в помощи сельским врачам. И проблема эта связана прежде всего с тем, что отсутствует какая-либо помощь для врачей, какая-то поддержка или вообще просто возможность коллегиального общения. И вот это все, конечно, может сделать всю работу просто невыносимой - от слова “совсем». (Ж., 30, терапевт, Республика Карелия)

\section{Смена модели взаимодействия молодых сельских врачей с пациентами}

В ходе тематического анализа интервью нам удалось выделить основные субтемы, описывающие повседневность сельских врачей. В предыдущем разделе мы отметили, что молодые специалисты акцентировали внимание на особенностях трансформации мотивации молодых врачей, спровоцированных пандемией COVID-19, их влиянии на работу и удовлетворенность ею, а также на состоянии профессионального фатализма, связанном с потерей экспертности и, как следствие, уверенности в своих знаниях (в отличие от периода до начала пандемии).

В этом разделе мы рассматриваем, как изменилась трудовая мотивация сельских докторов, принимая во внимание их переход от экспертной и патерналистской модели работы к новой модели взаимодействия врачей и пациентов модели смещения ролей. Модель смещения ролей означает, что пациенты в сельской местности часто сами решают, больны они или нет, и какое заболевание им необходимо лечить. Модель предполагает перераспределение ответственности между медицинскими сотрудниками и гражданами в лечении болезни. Основной особенностью модели выступает ослабление у пациентов патерналистских установок: врач больше не имеет экспертной монополии в лечении заболевания, он лишается возможности диктовать пациенту условия, связанные с госпитализацией. Таким образом, в этой модели врач воспринимается как равноправный агент, бессильный перед новой инфекцией.

В нарративах врачей переход к новой модели артикулировался посредством использования таких субтем, как "отсутствие возможностей для баланса между работой и отдыхом" и "потеря экспертности и профессионализма". При этом, говоря о будущем и о развитии медицинской профессии, молодые врачи использовали метафору хаоса, которая в целом характерна для описания ситуации пандемии. Важным представляется изменение мнения информантов о роли медицинской профессии, которая больше не воспринимается молодыми специалистами как исключительно экспертная. В нарративах информантов описывалось смещение 
экспертности в сторону диалога с пациентом, это артикулировалось как "находиться с пациентами на одних и тех же (равных) позициях". При этом необходимо отметить, что у врачей переход к новой модели вызывает тревогу, они по-прежнему считают приоритетной работу с пациентами в рамках патерналистской модели:

Просто знаете, если с авторитетом врача и его постепенной, скажем, девальвацией будут проблемы, такие как сейчас, то я считаю, что тогда вообще работать и незачем, особенно здесь. Все-таки врач - это специалист, который знает, как лечить и как рассказывать про новые болезни. А сейчас так получается: что ни говори пациенту, даже научно проверенные данные,-все как об стенку горох. (Ж., 26, врач общей практики, Республика Карелия)

Основными сквозными субтемами, в рамках которых молодые врачи описывали свою мотивацию к работе, были такие как "защита местного сообщества", "охранная роль в местном сообществе" и "особая роль медицинского специалиста на селе». Однако с наступлением пандемии COVID-19 патерналистская, защитная роль врача нивелировалась. В интервью молодые специалисты говорили о нежелании продолжать работать по профессии из-за произошедшей смены ролей.. Многие опрошенные нами специалисты отмечали, что желание сменить профессию вызвано тем, что в связи с пандемией COVID-19 роль врача претерпевает значительные изменения. Так, в сельской местности доктора утрачивают свой прежний экспертный статус:

Я считаю, что сейчас медицина стоит на пороге серьезного и, скажу так, структурного кризиса. И это вызвано в первую очередь тем, что роль врача изменяется. Если раньше здесь тебя нередко грел тот факт, что вот так, работая в сельской местности, ты можешь приносить пользу людям, то сейчас все наоборот, потому что теперь ты здесь не нужен, и не нужен из-за того, что не можешь дать серьезный ответ и противостоять этой угрозе, которая называется пандемией. (М., 35, терапевт, Республика Карелия)

Таким образом, ключевой субтемой, в рамках которой молодые врачи описывали снижение своей мотивации к работе, был переход от патерналистской к смешанной модели профессиональной деятельности, где врач из эксперта превращается в агента лечения, имеющего равные права и часто равные возможности с пациентами. Эта субтема превалировала в нарративах специалистов Питкярантского района Республики Карелия. Для молодых врачей Лужского района Ленинградской области, наряду с утратой патернализма, значимыми для снижения мотивации к работе в сельской местности также оказались субтемы, связанные с многозадачностью и потерей экспертности и профессионализма в период пандемии COVID-19.

\section{Заключение}

Целью нашего исследования было описание смыслов, вкладываемых молодыми сельскими врачами в свою работу в период пандемии COVID-19. Мы строили анализ особенностей их повседневной деятельности вокруг следующих тем: 
трансформация роли врача; изменение мотивации врачей к работе; вопросы удовлетворенности работой в сельской местности в период пандемии COVID-19. Эти три основные темы раскрываются в исследовании через такие субтемы, как:

- "отсутствие времени заниматься профилактическими работами";

- "новые обязанности";

- «необходимость лечения нового заболевания, которое требует новых знаний и навыков, что требует дополнительного времени";

- "субтема сельскости";

- "наличие средств индивидуальной защиты (СИЗ)";

- "отсутствие возможностей для баланса между работой и отдыхом»;

- «потеря экспертности и профессионализма»;

- "субтема уязвимости";

- "субтема администрирования в системе здравоохранения";

- «защита местного сообщества";

- "охранная роль в местном сообществе";

- "тема особой роли медицинского специалиста на селе».

Слабые и сильные стороны нашей работы определяются возможностями и ограничениями исследований, выполненных в качественной парадигме. Одними из главных недостатков оказываются субъективизм и невозможность построения обобщенных выводов. Тем не менее проведенные нами тридцать интервью посвящены глубинному изучению наиболее типичных случаев работы молодых врачей в период пандемии COVID-19.

Исследование особенностей работы врачей в сельской местности связано с выявлением их удовлетворенности работой в период пандемии COVID-19 и, при проведении количественного исследования, сопряжено с вероятностью получения социально одобряемых результатов. Качественный подход в данном случае рассматривается нами как хорошая альтернатива: детальное описание типичных случаев профессиональной деятельности молодых врачей в сельской местности в период пандемии позволяет взглянуть на особенности их повседневной работы "изнутри", получить их индивидуальные мнения и интерпретации ситуации.

Наши данные описывают причины снижения мотивации к работе и трансформации повседневной деятельности молодых сельских врачей в период пандемии COVID-19. Использование феноменологического подхода и метода секвенциального тематического анализа позволило прояснить субъективные представления специалистов о своем профессиональном мире.

В результате исследования оказалось, что молодые врачи относятся к группе риска, связанного с потерей мотивации к профессиональной деятельности, а также утраты желания продолжать работу в сельской местности. Потеря прежней мотивации к работе выступает одной из важнейших проблем для медицинских специалистов на селе и обуславливает их желание переехать в город или сменить род занятий. Возможности маркирования прежнего экспертного и патерналистского профессионализма, доступные молодым врачам до наступления пандемии, в особой социальной ткани сел и в ситуации особого общения и взаимодействия с пациентами изменяются, что влияет на мотивацию молодых специалистов работать на селе. 
Таким образом, ситуация пандемии переформатирует профессионализм сельских врачей. Поиск новой модели взаимодействия доктора и пациента, которая обозначена в исследовании как модель смещения ролей, носит болезненный характер для молодых специалистов. Вопрос заключается в том, какова будет эта новая роль: не традиционная, не патерналистская и не роль профессионала, способного решить любые задачи, а роль актора, участника процесса поиска нужного лечения от новой коронавирусной инфекции. При этом утрата прежней патерналистской модели взаимодействия может деструктивно влиять на принципы работы сельского врача и на особенности его общения с пациентами.

Применяя феноменологический подход и исследуя в нарративах интервью смыслы медицинской профессии и работы молодых врачей на селе, нам удалось выяснить, что прежнее значение профессионализма трансформируется: ему на смену приходит новое понимание и значение медицинского профессионализма, связанное с моделью смещения ролей во взаимодействии доктора с пациентом, что не всегда находит отклик у специалистов. Для молодых врачей такое смещение ролей становится одной из причин желания уехать из сельской местности, а также фактором снижения мотивации к профессиональной деятельности в целом.

\section{Список литературы (References)}

Андреева А.А. Психогигиена врача общей практики в сельской местности // Актуальные проблемы гигиены и экологической медицины: сб. материалов V межвуз. студенч. заоч. науч.-практ. конф. с международ. участием / ред. И. А. Наумов. Гродно, 2020. С. 15-18.

Andreeva A. A. (2020) Psychohygiena of a General Practitioner in Rural Areas. In: Naumov I. A. (ed.) Actual Problems of Hygiene and Environmental Medicine: Collection of Materials of the V Intercollegiate Student Correspondence Scientific and Practical Conference with International Participation. GrodNo. P. 15-18. (In Russ.)

Вяткина Н. Ю., Вахромеева А. Ю. Возрождение земской медицины: реалии и перспективы // Социология медицины. 2012. № 2. С. 38-40.

Vyatkina N. Yu., Vakhrameeva A. Yu. (2012) The Revival of Zemstvo Medicine: Realities and Prospects. Sociology of Medicine. No. 2. P. 38-40. (In Russ.)

Галкин К.А. Карьерные стратегии молодых сельских врачей ленинградской области: нарративный анализ // Вестник Пермского университета. Философия. Психология. Социология. 2018. № 1. С. 158-167.

Galkin K. A. (2018) Career Strategies of Young Rural Doctors of the Leningrad Region: Narrative Analysis. Bulletin of the Perm University. Philosophy. Psychology. Sociology. No. 1. P. 158-167. (In Russ.)

Галкин К.А. Когда работа не заканчивается: профессиональные роли и отношение к помощи в нерабочее время у молодых сельских врачей // Мониторинг общественного мнения: экономические и социальные перемены. 2019. № 3. С. 179-190. https://doi.org/10.14515/monitoring.2019.3.11.

Galkin K. A. (2019) When Work Never Ends. Professional Roles and Attitudes of Young Rural Doctors to Patient Care in the off-Hours. Monitoring of Public Opinion: 
Economic and Social Changes Journal. No. 3. P. 179-190. https://doi.org/10.14515/ monitoring.2019.3.11. (In Russ.)

Галкин К.А. Молодые врачи в городе и в селе: особенности профессиональной идентичности // Мир России. 2020. Т. 29. №3. С. 142-161. https:// doi.org/10.17323/1811-038X-2020-29-3-142-161.

Galkin K. A. (2020) Young Physicians in the City and in the Countryside: Features of Professional Identity. Universe of Russia. Vol. 29. No. 3. P. 142-161. https:// doi.org/10.17323/1811-038X-2020-29-3-142-161. (In Russ.)

Гранберг Л. Структурные изменения в сельской местности России и Финляндии сравнительный анализ двух различных типов общества // Мир России. 2015. Т. 24. № 3. С. $160-175$.

Granberg L. (2015) Structural Change in Finnish and Russian Countrysides: a Comparative Analysis of Two Different Types of Society. Universe of Russia. Vol. 24. No. 3. P. $160-175$. (In Russ.)

Дьяченко В.Г., Костакова Т.А., Пригорнев В.Б. Профессиональные мотивации будущих врачей // Вестник общественного здоровья и здравоохранения Дальнего Востока России. 2011. Т. 2. С. 1-7.

Dyachenko V. G., Kostakova T. A., Prigornev V.B. (2011) Professional Motivations of Future Doctors. Russian Far East Public Health and Health Bulletin. Vol. 2. P. 1-7.

Кобякова О. С., Деев И.А., Куликов Е. С., Хомяков К. В., Тюфилин Д. С., Загромова Т. А., Балаганская М.А. Профессиональное выгорание врачей различных специальностей // Здравоохранение Российской Федерации. 2017. Т. 61. № 6. C. $322-329$.

Kobyakova O.S., Deev I. A., Kulikov E.S., Khomyakov K. V., Tyufilin D. S., Zagromova T. A., Balaganskaya M. A. (2017) Professional Burnout of Doctors of Various Specialties. Healthcare of the Russian Federation. Vol. 61. No. 6. P. 322-329. (In Russ.)

Майвальд К.-О. Секвенциальный анализ в немецкой социологии: компетенция и практика // Социология: методология, методы, математическое моделирование (Социология: 4М). 2011. № . 32. С. 143-180.

Maiwald K.-O. (2011) Competence and Praxis: Sequential Analysis in German Sociology. Sociology: Methodology, Methods, Mathematical Modeling (Sociology: 4M). No. 32. P. 143-180. (In Russ.)

Петрова Л.Е. Поколенческие различия в социально-профессиональной группе врачей как фактор качества оказания медицинской помощи // Социальные аспекты здоровья населения. 2014. № 3. С. 8.

Petrova L.E. (2014) Generational Differences in the Socio-Professional Group of Doctors as a Factor in the Quality of Medical Care. Social Aspects of Public Health. No. 3. P. 8. (In Russ.)

Романов П. В., Ярская-Смирнова Е. Р. Мир профессий: пересмотр аналитических перспектив // Социологические исследования. 2009. № 8. С. 25-35.

Romanov P. V., Yarskaya-Smirnova E. R. (2009) The World of Professions: Revision of Analytical Perspectives. Sociological Studies. No. 8. P. 25-35. 
Романов П. В., Ярская-Смирнова Е. Р. Идеологии профессионализма и социальное государство // Антропология профессий, или посторонним вход разрешен. М.: Вариант, ЦСПГИ. 2011.

Romanov P.V., Yarskaya-Smirnova E. R. (2011) Ideologies of Professionalism and the Social State. Anthropology of Professions, or Unauthorized Entry Allowed. Moscow: Variant, TSSPGI. (In Russ.)

Семина Т.В. Социологические аспекты дисбаланса взаимоотношений медицины и населения в современной России // Вестник Российского университета дружбы народов. Серия: Социология. 2015. Т. 15. № 3. С. 70-79.

Semina T. V. (2015) Sociological Aspects of Medicine and Population Unbalanced Relationships in Contemporary Russia. RUDN Journal of Sociology. Vol. 15. No. 3. P. 70-79. (In Russ.)

Чирикова А. Е. О полимотивации врачей: уроки реформ // Мир России. 2019. Т. 28. № 3. C. 6-26. https://doi.org/10.17323/1811-038X-2019-28-3-6-26.

Chirikova A. E. (2019) On the Multiple Motivations of Physicians: Lessons from Reforms. Universe of Russia. Vol. 28. No. 3. P. 6-26. https://doi.org/10.17323/1811038X-2019-28-3-6-26. (In Russ.)

Шилова Л. С. Модернизация российского здравоохранения: вызовы, ожидания и реальность // Вестник института социологии. 2013. № 6. С. 146-162.

Shilova L.S. (2013) Modernization of Russian Healthcare: Challenges, Expectations and Reality. Bulletin of the Institute of Sociology. No. 6. P. 146-162. (In Russ.)

Широкалова Г. С., Дерябина О.Н. Специалисты для села и село для специалистов // Социологические исследования. 2010. № 9. С. 26-39.

Shirokalova G.S., Deryabina O. N. (2010) Specialists for the Village and Village for Specialists. Sociological Studies. No. 9. P. 26-39. (In Russ.)

Alhojailan M.I. Thematic Analysis: A Critical Review of Its Process and Evaluation. West East Journal of Social Sciences. 2012. Vol. 1. No. 1. P. 39-47.

Woods M. (2012) New Directions in Rural Studies. Journal of Rural Studies. Vol. 28. No. 1. P. $1-4$.

Amoafo E., Hanbali N., Patel A., Singh P. (2015) What are the Significant Factors Associated With Burnout in Doctors? Occupational Medicine. Vol. 65. No. 2. P. 117121. https://doi.org/10.1093/occmed/kqu144.

Budhathoki S. S., Zwanikken P., Pokharel P., Scherpbier A. (2017) Factors Influencing Medical Students' Motivation to Practise in Rural Areas in Low-Income and MiddleIncome Countries: A Systematic Review. BMJ Open. Vol. 7. No. 2. P. 12-15. https:// doi.org/10.1136/bmjopen-2016-013501.

Driever E. M., Stiggelbout A. M., Brand P.L. P. (2020) Shared Decision Making: Physicians' Preferred Role, Usual Role and Their Perception of Its Key Components. Patient Education and Counseling. Vol. 103. No. 1. P. 77-82. https://doi.org/10.1016/j.pec. 2019.08.004. 
Glenister K. M., Ervin K., Podubinski T. (2021) Detrimental Health Behaviour Changes Among Females Living in Rural Areas During the COVID-19 Pandemic. International Journal of Environmental Research and Public Health. Vol. 18. No. 2. P. 722. https:// doi.org/10.3390/ijerph18020722.

Huberman M., Miles. M. B. (1994) The Qualitative Researcher's Companion. New York: Sage Publications. 424 p.

Kvale S. (1996) Interviews: An Introduction to Qualitative Research Interviewing Thousand Oaks. New York: Sage Publications. 326 p.

Kumar S. (2016) Burnout and Doctors: Prevalence, Prevention and Intervention. Healthcare. Vol. 4. No. 3. P. 37. https://doi.org/10.3390/healthcare4030037.

Kusurkar R.A., Cate Th., van Asperen M., Croiset G. (2011) Motivation as an Independent and a Dependent Variable in Medical Education: A Review of the Literature. Medical Teacher. Vol. 33. No. 5. P. 242-262. https://doi.org/10.3109/ $0142159 \times .2011 .558539$.

Ohta R., Ryu Y., Otani J. (2020) Rural Physicians' Perceptions About the Challenges of Participating in Interprofessional Collaboration: Insights From a Focus Group Study. Journal of Interprofessional Education \& Practice. Vol. 20. P. 100-345. https:// doi.org/10.1016/j.xjep.2020.100345ю

Pathman D., Konrad T., Dann R., Koch G. (2004) Retention of Primary Care Physicians in Rural Health Professional Shortage Areas. American Journal of Public Health. Vol. 94. No. 10. P. 1723-1729. https://doi.org/10.2105/ajph.94.10.1723.

Saijo Y., Yoshioka E., Hanley S. J.B., Kitaoka K., Yoshida T. (2018) Job Stress Factors Affect Workplace Resignation and Burnout Among Japanese Rural Physicians. The Tohoku Journal of Experimental Medicine. Vol. 245. No. 3. P. 167-177. https:// doi.org/10.1620/tjem.245.167.

Serneels P., Montalvo J. G., Pettersson G., Lievens T., Buterae J. D., Kidanu A. (2010) Who Wants to Work in a Rural Health Post? The Role of Intrinsic Motivation, Rural Background and Faith-Based Institutions in Ethiopia and Rwanda. Bulletin of the World Health Organization. Vol. 88. P. 342-349. https://doi.org/10.2471/blt.09.072728.

Todd A., Holmes H., Pearson S., Hughes C., Andrew I., Baker L., Husband A. (2016) 'I Don't Think l'd Be Frightened if the Statins Went': A Phenomenological Qualitative Study Exploring Medicines Use in Palliative Care Patients, Carers and Healthcare Professionals. BMC Palliative Care. Vol. 15. No. 1. P. 1-7. https://doi.org/10.1186/ s12904-016-0086-7. 